tion too early has long been recognised as undesirable. Dr St Leger is also clearly unaware that even those fortunate enough to be exempted from part I MFCM examinations have nevertheless to pay the fees for them, as otherwise he would recognise that the present policies of the Faculty of Community Medicine are founded on educational grounds rather than fiscal ones. After reading his letter it is hard to resist the temptation to generalise and conclude that perhaps after all the present policies are the right ones.

Manchester

DAVID J HewetT

'Beer, S, Decision and Control. New York, Wiley, 1966. Ackoff, R L, and Sasieni, M W, Fundamentals
Operational Research. New York, Wiley, 1968.

SIR,-As trainee community physicians and presumably therefore future "mediocre "Jacksof-all-trades', we take strong exception to Dr A S St Leger's letter (20 March, p 709).

His sweeping dismissal of sociology and administrative theory suggests nothing if not an "uncritical assimilation of received opinion," to use his own phrase, while his equating community medicine with administration reveals an ignorance of this field confirmed by the assertion that trainees uncritically accep the contents of their courses. As any teacher on the modular courses will confirm, we provide constant critical feedback which has helped to modify and improve our training.

From our "superficial" study of epidemiology we understand that it is based on the construction of logical hypotheses from carefully observed and quantified facts. We can therefore understand Dr St Leger's apprehension at the prospect of being obliged to sit part I of the MFCM but do not feel that the correct remedy lies in altering the examination requirements.

Sheila AdAM $T$ W DAVIES

GRAHAM WINYARD

M S RIGLER

$S$ FRANCIS

Department of Social Medicine,

University of Oxford

\section{Constipation and soiling in childhood}

SIR,-In my view Dr G S Clayden (28 February, p 515) overemphasises the importance of mechanical factors in the causation and treatment of this problem and fails to give sufficient weight to psychological environmental influences.

In this connection I would like to comment on the short-term outcome of 50 consecutive cases of severe soiling admitted to two hospital units for psychiatrically disturbed children situated near the city of Leeds because of failure of outpatient treatment, social factors, and severe associated problems. The mean age on admission was 8 years. They were managed on a weekly basis and remained an average of 5 months. Faecal retention was present to some extent in the majority and was severe in one-third, in whom it responded to oral laxatives within a matter of weeks. Half the group had associated enuresis. Half were severely disturbed, mainly with conduct disorders. Half had very unsatisfactory home conditions. Two-thirds appeared to need the constant attention of concerned adult to establish a normal bowel habit. All had stopped soiling for at least a month on discharge. Parents were involved in treatment as far as possible and had the children home every weekend. We do not know the long-term outcome yet, although a follow-up study is currently being attempted. Whatever the original cause it seemed that the constipation and soiling had persisted in these children prior to admission because of the psychological environmental influences consequent on soiling, mainly the reaction of parents and other children. Once faecal retention was overcome because of the relaxed atmosphere and the use of oral laxatives it was still necessary to help the child develop a normal bowel habit. This aspect of the problem was hardly mentioned by Dr Claydon. Mechanical emptying procedures used from below were not necessary at all. In fact some children appeared to have developed psychiatric symptoms, such as phobias, in response to their previous use. Dr Claydon does not refer to the likelihood of this happening.

It can, of course, be argued reasonably that this was a very biased sample of soilers. However, similar findings were reported previously in the treatment of constipated soilers by oral laxatives and regular outpatient visits in a paediatric setting, with good results. ${ }^{1}$ Also, in a group of 8-year-old children from the general population of Stockholm² it was considered that punitive reactions of mothers to the occurrence of soiling and embarrassment engendered by soiling at school were two factors encouraging faecal retention, and it was found that soiling children were somewhat reluctant to use the toilet.

Some doctors have managed to dispense with laxatives altogether and manage constipated soilers entirely as a psychological problem. ${ }^{3}$ I still find that quite large doses of oral laxatives may be necessary to reduce faecal retention while the child remains at home. It may be advisable in young children to keep them off school for a few weeks until a regular bowel habit is established. The most important aspect of management, however, is to support the mother so that she can stop reacting severely to the soiling and give the child plenty of encouragement when he or she starts to use the toilet regularly in the hopefully, more relaxed atmosphere at home.

\section{IAN BERG}

Kanner Children's Unit,
High Royds Hospital,

${ }^{1}$ Berg, I, and Jones, K V, Archives of Disease in Childhood, 1964, 39, 465.

Bellman, M, Acta Paediatrica Scandinavica, 1966 170, suppl, p 1.

Jolly, $\mathrm{H}$, Proceedings of the Royal Society of Medicine, 1976, 69, 21.

\section{Herpesvirus and cervical cancer}

SIR,-I read with interest the latest (20 March, p 671) of the excellent series of leading articles you have produced on the relationship of carcinoma of the cervix to infections with herpes simplex virus type 2 (HSV 2).

As a venereologist I have been increasingly concerned about many aspects of genital herpetic infections, which are occurring nowadays with increasing frequency. This illness can be an extremely severe one for women, primary infections causing great pain, agonising dysuria, difficulty with micturition, and even retention of urine. Systemic reaction with high fever is common and meningeal involvement may develop. Herpetic cervicitis may be clinically obvious and severe, though the virus can frequently be recovered from a slightly inflamed or indeed apparently normal cervix in patients suffering from herpetic vulvitis.
Although most of the published work associates the genital strain of $\mathrm{HSV}$ with carcinoma of the cervix, many, if not the majority, of the cases of genital herpes seen, in my experience, follow orogenital intercourse and are therefore presumably due to type 1 or oral strains. We do not know if this strain shares the putative oncogenic potential of HSV 2, but if it does, judging by the number of cases currently being seen, a veritable epidemic of cervical dysplasia, carcinoma-insitu, and carcinoma of the cervix should be observed in the next $10-20$ years.

Many cases of genital herpes are not diagnosed as they present to the doctor as "cystitis" or "dysuria" and I would stress that every woman complaining of extreme dysuria should have her vulva carefully inspected as such a symptom nearly always means that genital herpes is present. I would strongly support the suggestion made in your article that an accurate diagnosis, preferably by culture of the virus, should be made whenever possible and I think that cytological review should be carried out (regardless of age) at at least yearly intervals in all women who have sustained an attack of herpetic cervicitis until the role the virus plays (if any) in the development of carcinoma of the cervix is more precisely defined.

J K OAtes

Westminster Hospital,

Westminster

\section{Metabolic effects of bran}

SIR,-In the studies of $\mathrm{Mr}$ A J M Brodribb and Dr Daphne $M$ Humphreys (21 February, p 428) glucose tolerance curves were flatter in 37 patients tested with $50 \mathrm{~g}$ oral glucose after eating $24 \mathrm{~g}$ wheat bran daily for more than six months. This is of particular interest in view of the evidence that dietary fibre and other unabsorbable carbohydrates modify carbohydrate tolerance. Jeffreys ${ }^{1}$ reported that bran decreased blood glucose levels when taken with glucose syrup and we have found that unabsorbable polysaccharides decreased postprandial glycaemia following a liquid meal containing glucose. ${ }^{2}$ The latter observation has been repeated after solid "breakfast" meals in which guar gum (a storage polysaccharide from the cluster bean) and pectin (a polymer of galactouronic acid obtained from apples) were added to the bread and marmalade respectively. After an overnight fast each of five healthy volunteers ate a test and control meal in randomised order on two mornings 48 hours apart. The carbohydrate load $(105 \mathrm{~g})$ was the same in each meal. The mean maximum rise of blood sugar after the guar/pectin meal was only $40 \%$ of the control value $(P<0.002)$. Mean insulin levels were significantly lower after the guar/pectin meal, being only $35-54 \%$ of the corresponding control levels. Mean differences between test and control insulin levels ranged from $26 \pm 5$ to $37 \pm 5 \mathrm{mU} / \mathrm{l}$.

Van der Westhuizen $e t a^{3}$ have suggested that the flatter glucose tolerance curves seen in groups eating large quantities of maize meal ${ }^{4}$ may be due to an adaptation of the more distal part of the small intestine for glucose absorption. An alternative idea is that when natural unprocessed foods are eaten glucose absorption occurs equally well in any part of the jejunum, but that the consumption of refined carbohydrate by "Western" societies has resulted in an improved ability of the 
proximal jejunum to absorb glucose. The trapping of available carbohydrate within intact cell walls and alterations of the physical characteristics of the intraluminal contents by unabsorbable carbohydrates may both result in reduced availability of glucose for absorption in the proximal small bowel while increasing its availability in the distal small bowel. The adaptation of the proximal jejunum may then be reversed, resulting in a flatter glucose tolerance curve.

It is possible that some diabetic patients might benefit from treatment with wheat bran or other dietary fibres and unavailable carbohydrates.

ANTHONY LeEDS

M A Gassuli

D J A JENKINS K G M M AlberTi

MRC Gastroenterology Unit,
Central Middlesex Hospital,

London NW10

University Chemical Pathology and

Human Metabolism Unit,

Southampton

1 Jeffreys, D B, Proceedings of the Nutrition Society, 1974, 33, 11A.

' Leeds, A R, et al, Lancet, 1975, 2, 1213. Lancet, 1972, 2 , 719.

- Wapnick, S, et al, Lancet, 1972, 2, 300.

\section{Student counselling}

SIR,-Your leading article (13 March, p 605) is timely. It does not, however, adequately emphasise weaknesses in the present situation in Britain nor point to the future. What is the prevalence of student problems ? How should they be managed? How might they be diminished or prevented?

A review of prevalence studies ${ }^{1}$ suggests that, over all faculties, $1-5 \%$ of students suffer from serious personality problems or psychiatric disability and a further $10-20 \%$ from a miscellany of difficulties: minor psychiatric disturbance, problems with living, study difficulties, ${ }^{2}$ psychosocial and psychosexual problems, ${ }^{3}$ psychosomatic disturbances. This minor morbidity can lead to considerable personal unhappiness, and, more relevant, is eminently treatable. Management involves counselling techniques ${ }^{4}$ as well as other forms of treatment not mentioned in your article, principally psychotherapy, both psychodynamic $^{5}$ and behavioural. ${ }^{6}$ All three forms of treatment should be available and crucially, as you mention, there should be close harmony with the academic tutorial system. From experiences $^{7}$ I have no doubt that liaison between these helping services is far more effective than either academic or psychological guidance alone. These treatment techniques are as yet available only to a small-it is not accurately known how small-percentage of students in higher education, in both the university and non-university sectors. Medical schools in London are conspicuous for their backwardness in introducing any comprehensive helping service relevant to students other than formal psychiatric treatment, including psychotherapy, provided by psychiatrists.

With current emphasis rightly on preventive medicine, other related measures should be considered which might lessen the burden on counsellers and others. With sexual and relationship problems so important in the student age group, sex education ${ }^{8}$ is surely high $\sim$ the list of priorities, especially for medical students, who should, as doctors, be in a position to pass on their expertise to their patients. Comprehensive sex education needs the cooperation of persons with special areas of expertise-anatomy, physiology, sociology, psychology, psychiatry, gynaecology-but this has been achieved elsewhere as, for example, in Denmark. ${ }^{9}$ As with counselling, so with sex education, London medical schools keep their heads firmly in the sand so that those, like me, with a special interest in this area of medical education may be offered two one-hour periods in a behavioural science course to teach human sexuality. Given these constraints, one is either arguing with the sexually experienced student or frightening the inexperienced.

The time has come to make a positive contribution to the personal fulfilment of students. Counselling, psychotherapy, behavioural modification, co-ordination with academic tutors, and sex education represent a systematic attempt to reduce the incidence of new problems or, where prevention fails, to provide a more effective and co-ordinated programme of management.

SIDNEY CROWN

The London Hospital,

London E1

${ }^{1}$ Lucas, C J, and Crown, S, British fournal of Psychiatry, 1974, 125, 595.
Crown, S, Lucas, C J, and Supramaniam, S, British
fournal of Psychiatry, 1973, 123, 381 .

Fournal of Psychiacry, 1973, 123, 381. Counselling and Behavioural Modification, ed Crown, $\mathrm{p}$ 157. London, Academic Press. In press.

Newsome, A, in Psychosexual Problems: Psychotherapy Counselling and Behavioural Modification, ed Crown, p 59. London, Academic Press. In press.

Crown, S, in Issues and Approaches in the Psychological Therapies, ed D Bannister, p 187. London, Wiley,

eyer, V, and Liddell, A, in Issues and Approaches in the Psychological Therapi

' Crown, S, University Quarterly, 1970, 24, 422.

Cole, M, in Psychosexual Problems: Psychotherapy Counselling and Behavioural Modification, ed Crown, p 433. London, Academic Press. In press. Bechnann, J, et al, British fournal of Medical Education, 1975, 9, 114.

\section{Assessment of preoperative cases}

SIR,-Dr P R Fletcher's letter (6 March p 580) commenting on Dr T W Ogg's article (10 January, p 82) stimulated me to survey 230 outpatient cases I had anaesthetised using a questionnaire similar to that used by Dr Ogg. The series included 133 dental and 97 genitourinary cases. The dental cases were evenly distributed in regard to sex but in the genitourinary series $61.8 \%$ were males. The age distribution was as follows.

\begin{tabular}{|c|c|c|c|}
\hline \multirow{2}{*}{$\begin{array}{c}\text { Age } \\
\text { (years) }\end{array}$} & & No of patients & \\
\hline & Dental & Genitourinary & Total \\
\hline $\begin{array}{r}2-16 \\
17-45 \\
46-65 \\
66-83\end{array}$ & $\begin{array}{r}67 \\
59 \\
6 \\
1\end{array}$ & $\begin{array}{r}0 \\
43 \\
35 \\
19\end{array}$ & $\begin{array}{r}67 \\
102 \\
41 \\
20\end{array}$ \\
\hline
\end{tabular}

Of the 169 patients aged $2-45,10 \cdot 1 \%$ had medical histories and $31.3 \%$ were on concurrent drug therapy. The corresponding proportions of the 61 patients aged $46-83$ were $19.6 \%$ and $32.6 \%$ respectively. Of the patients aged $2-45,4.7 \%$ gave a history of allergy, and of those aged $46-83,6.5 \%$ gave a similar history. No patient under 17 admitted to smoking, but $33.3 \%$ of those aged 17-45 and $45.9 \%$ of those aged $46-83 \mathrm{did}$ so.

Anaesthesia was postponed in no case in the series, but consideration was given to one girl aged 17 weighing $15.5 \mathrm{~kg}$ who presented for exodontia cyanosed and with marked finger-clubbing. She was not dyspnoeic, however, and perusal of her questionnaire revealed a history of chronic cystic fibrosis and that she was on ampicillin.

The questionnaire appeared to be a useful screen in all age groups, but undoubtedly the institution of preoperative clinics would be the ideal.

W N Rollason

University Medical Buildings,

Aberdeen

\section{Spasmolytics for postoperative bowel} contractions

SIR,-In the search for a suitable spasmolytic agent to antagonise neostigmine-induced bowel contractions (Drs E N S Fry and S Deshpande, 13 March, $p$ 646) hyoscine butylbromide was likely to prove disappointing. Most workers have found its nicotinic to predominate over its muscarinic actions in keeping with its quaternary ammonium structure so that it is a poor antagonist of the local accumulation of acetylcholine.

Alternatives might include another anticholinergic drug, propantheline bromide, with strong selective muscarinic properties in addition to its nicotinic effects. Herxheimer ${ }^{1}$ reported a spasmolytic potency of 3-75 in comparison with atropine, while the antisialogogue potency was 0.76 and the heart acceleration potency was $0 \cdot 70$. As with hyoscine butylbromide, however, duration of action was brief. ${ }^{2}$ Among those spasmolytics acting directly, papaverine may have a place as it is reported to have 50 times the potence of hyoscine butylbromide in inhibiting barium chloride spasms. ${ }^{3}$ Mebeverine in turn was found to be more potent than papaverine by Lindner, ${ }^{4}$ and Connell ${ }^{5}$ was able to demonstrate a decrease in colonic muscle motility lasting 10-35 minutes in man after $50 \mathrm{mg}$ given intravenously.

While searching for the ideal spasmolytic for use in conjunction with neostigmine one would like to have some more information to what extent ruptured intestinal anastomoses are a problem in association with neostigmine, bearing in mind that all the subjects in Bell's study $^{6}$ had had steroid therapy and that anastomotic leakage was demonstrated radiologically with barium, not clinically.

J W H WATT

Department of Anaesthesia,

Walton Hospital,
Liverpool

Herxheimer, A, British fournal of Pharmacology, 1958, $13,184$.

Barowsky, $\mathrm{H}$, et al, American fournal of Digestive $1965,10,506$

ick, H, Archiv für experimentelle Pathologie und Pharmakologie, 1951, 213, 485.

indner, A, et al, Archives Internationales de Pharmacodynamie et de Thérapie, 1963, 145, 378.

Connell, A M, British Medical fournal, 1965, 2, 848.

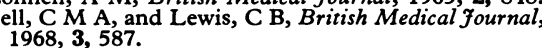

\section{High intestinal lactase in Pakistanis}

SIR,-Though I have no means of questioning the technical validity of the paper by Drs $S M$ Rab and A Baseer (21 February, p 436), I would like to make the following comments on their ethnic conclusions.

(1) Punjabis, though depicted as a Mediterranean race, are actually a product of the 